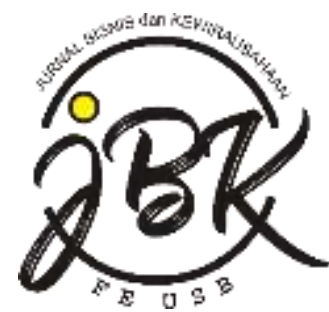

ISSN : 2302-1322

Volume 13/Nomor-1/April /2020

\title{
DETERMINAN PERILAKU KEWARGANEGARAAN ORGANISASIONAL (OCB) PETUGAS DI RUMAH SAKIT
}

Yohana E Wonga ${ }^{1}$,

Fakultas Ekonomi, Universitas Setia Budi

(raymudasr@yahoo.com)

Nang Among Budiadi ${ }^{2}$

Fakultas Ekonomi, Universitas Setia Budi

(nangamongbudiadi@gmail.com)

Sugiyarmasto ${ }^{3}$

Fakultas Ekonomi, Universitas Setia Budi

(syarmasto@gmail.com)

Ariefah Yulandari ${ }^{4}$

Fakultas Ekonomi, Universitas Setia Budi

(yulan_fe@setiabudi.ac.id)

\begin{abstract}
This study was aimed to examine the effect of job satisfaction and organizational commitment to $O C B$, the effect of job satisfaction on organizational commitment, the effect of organizational justice to job satisfaction and organizational commitment, the influence of superordinate support to job satisfaction and organizational commitment. Sample was determided by using probability cluster sampling method and random sampling.The sample were staffs of Psychiatric Hospital and PKU Muhammadiyah Hospital in Surakarta. Data collection using questionnaires was distributed directly as many as 200 questionnaires. Data analysis was conducted by using SEM. The results showed that job satisfaction had a positive effect on OCB, organizational commitment had no effect on OCB. Job satisfaction had no effect on organization commitment. The value of organizational justice to job satisfaction shows significant effect, but not on organizational commitment. Superordinate support had no effect on job satisfaction and organizational commitment.
\end{abstract}

Keywords: OCB, job satisfaction, organizational commitment, organizational justice, superordinate support.

\section{A. PENDAHULUAN}

Globalisasi yang melanda rumah sakit mengakibatkan kompetisi, teknologi yang semakin canggih, kemajuan komunikasi, peraturan dan hukum yang lebih ketat dan berubah dengan cepat, ketidakstabilan politik, perubahan demografi tenaga kerja, serta pelanggan semakin kritis terhadap kualitas pelayanan. Oleh karena itu dibutuhkan fleksibilitas petugas kesehatan di rumah sakit untuk menyesuaikan diri dengan lingkungan yang terus berubah dan mencapai keunggulan kompetitif (Ocampo, 2018).

Rumah sakit memiliki banyak keunikan yang tidak ditemukan pada organisasi 
lainnya di mana merupakan suatu badan usaha yang padat karya, padat modal, padat teknologi dan padat konflik. Berbagai keunikan tersebut menimbulkan konsekuensi konsep dan kebijakan rumah sakit yang terus berkembang dari era pra global yang hanya menekankan aspek kuratif dan rehabilitatif menuju era global yang menekankan pada upaya paripurna meliputi aspek promotif, preventif, kuratif dan rehabilitatif (UU RI no.44 tahun 2009). Konsekuensi perubahan konsep dan kebijakan tersebut membutuhkan banyak waktu dan keterlibatan petugas di luar dari tugas pokoknya. Menurut Organ (1988) dalam Podsakoff et al. (2000), OCB merupakan perilaku sukarela individu di luar dari tugas pokoknya, tidak secara eksplisit diakui dalam sistem penghargaan formal namun mendukung kinerja organisasi secara efisien dan efektif.

Mohammad et al. (2011) menyatakan bahwa OCB disebabkan oleh kepuasan kerja. Penelitian lain menemukan bahwa OCB dipengaruhi oleh komitmen karyawan pada organisasi (Zayas-Ortiz et al., 2015). Di samping itu, Yucel dan Bektas (2012) menemukan adanya hubungan positif antara kepuasan kerja dan komitmen organisasional. Penelitian lain lagi yang dilakukan oleh Aksoy dan Yalcinsoy (2018) menjelaskan bahwa terdapat hubungan positif antara keadilan organisasional, dukungan atasan, kepuasan kerja dan komitmen karyawan pada organisasi. Terlihat ada keberagaman hasil penelitian empiris mengenai konstruk penjelas OCB. Di sampang itu, penelitian OCB yang dilakukan di sektor rumah sakit dengan melibatkan seluruh petugas rumah sakit masih jarang ditemukan. Penelitian ini akan mengintegrasikan faktor-faktor penjelas OCB yang berbeda tersebut ke dalam sebuah kerangka model penelitian terpadu dengan menggunakan obyek organisasi rumah sakit.

\section{B. LANDASAN TEORI}

OCB

OCB merupakan sebuah perilaku sukarela, tidak termasuk dalam deskripsi kerja formal anggota organisasi namun mendukung keberhasilan organisasi secara menyeluruh (Organ, 1988 dalam Dunlop dan Lee, 2004). OCB memberikan kontribusi bagi pemeliharaan serta peningkatan hubungan sosial dan psikologis yang mendukung kinerja pekerjaan (Organ, 1997). Perilaku sukarela tersebut meskipun tidak secara langsung diakui dalam sistim penghargaan formal, namun sangat mendukung fungsi efisiensi dan efektivitas organisasi (Podsakoff et al., 2006).

\section{Kepuasan Kerja}

Kepuasan kerja didefinisikan oleh Locke (1983) dalam Mohammad et al. (2011) sebagai keadaan emosi positif yang dialami seseorang berdasarkan hasil pekerjaanya. Penelitian Weiss (2002) menemukan bahwa kepuasan kerja yang dialami oleh karyawan tidak hanya berkaitan dengan hasil pekerjaan, tetapi juga menyangkut relasi 
yang baik dengan rekan kerja, pelanggan, atasan, dan lain-lain. Menurut Hoş dan Oksay (2015), kepuasan kerja sangat penting untuk meningkatkan produktivitas karyawan. Produktivitas kerja yang tinggi memberikan kebahagiaan dan kesuksesan. Karyawan yang merasa puas karena memiliki kemampuan dan kondisi kerja yang baik akan termotivasi untuk juga memberikan pelayanan yang berkualitas unggul kepada pelanggan (Salanova et al., 2011).

Berbagai studi terdahulu mengemukakan adanya hubungan positif antara kepuasan kerja dan OCB (Mohammmad et al., 2011; Swaminathan dan Jawafar, 2013; Saxena et al., 2019). Studi empiris yang dilakukan oleh Belwalkar et al. (2018) menemukan bahwa kepuasan kerja merupakan prediktor terkuat dari

OCB. Atas dasar berbagai eksplanasi yang dibangun dalam konstruk di atas, maka dapat diajukan hipotesis:

$\mathrm{H} 1$ : Kepuasan kerja berpengaruh positif pada OCB

\section{Komitmen Organisasional}

Komitmen organisasional adalah keyakinan individu terhadap nilai-nilai dan pencapaian tujuan organisasi serta bersedia untuk tetap tinggal dalam organisasi (Porter et al., 1974). Konsep serupa dikemukakan oleh Aksoy et al. (2018) bahwa komitmen organisasional sebagai sebuah ikatan psikologis yang menggambarkan tingkat pengorbanan karyawan bagi organisasi, kesediaan untuk taat serta menyelaraskan tujuan dan nilai organisasi ke dalam tujuan dan nilai mereka sendiri dalam proses interaksi timbal balik. Karyawan yang memiliki komitmen terhadap organisasi akan secara teratur datang ke tempat kerja dan melindungi aset organisasi (Meyer dan Allen, 1997 dalam Aksoy, 2018). Meyer dan Allen (1991) membagi komitmen organisasional menjadi tiga dimensi yaitu komitmen afektif, komitmen berkelanjutan dan komitmen normatif. Komitmen afektif mengacu pada ketergantungan emosional, kecenderungan psikologis yang positif dan kontribusi atau pengorbanan karyawan untuk organisasi. Komitmen berkelanjutan mencerminkan besarnya biaya yang dikeluarkan oleh karyawan bila meninggalkan organisasi. Komitmen normatif berarti bahwa karyawan dibatasi oleh normanorma sosial dan kemudian mengembangkan rasa tanggung jawab dan kewajiban untuk tinggal dalam organisasi.

Berbagai studi sebelumnya telah membahas adanya hubungan positif antara komitmen organisasional dan OCB (Salehi dan Gholtash, 2011; Khan dan Mohd (2012); Chun et al., 2013; Zayas-Ortiz et al., 2015). Khan dan Mohd (2012) menemukan bahwa komitmen organisasional memiliki pengaruh paling kuat dibandingkan budaya organisasi, gaya kepemimpinan dan keadilan organisasional. Hal ini membawa pada hipotesis:

$\mathrm{H} 2$ : Komitmen organisasional berpengaruh positif pada OCB. 
Hubungan antara komitmen organisasional dan kepuasan kerja juga telah diakui dengan baik. Organisasi yang mampu memenuhi kebutuhan karyawan di tempat kerja akan mendorong karyawan untuk tinggal dalam organisasi dan secara khusus terlibat mengambil peran dalam organisasi (Kirkman dan Shapiro, 2001). Crow et al. (2012) menemukan kepuasan kerja memiliki pengaruh yang lebih tinggi terhadap komitmen organisasional dibandingkan keadilan organisasional dan pengalaman kerja. Penelitan lain oleh Yucel dan Bektas (2012) menjelaskan bahwa kepuasan kerja sebagai prediktor kuat dari komitmen organisasional. Berbagai hasil peneltian selanjutnya menguatkan dukungan akan adanya korelasi positif antara kedua variabel di atas (Hos dan Oksay, 2015; Yao et al., 2019). Hal ini membawa pada hipotesis:

H3: Kepuasan kerja berpengaruh positif pada komitmen organisasional

\section{Keadilan Organisasional}

Keadilan organisasional merupakan seperangkat aturan dan norma sosial mengenai bagaimana distribusi sumber daya organisasi, prosedur yang digunakan dalam penentuan keputusan distribusi dan perilaku antarpribadi yang terjadi selama pelaksanan prosedur tersebut (Folger dan Cropanzono, 1998:110-111 dalam Aksoy et al., 2018). Keadilan organisasional terkait dengan keadilan distribusi (upah, promosi, dan lainlain) yang diterima oleh karyawan dari otoritas yang lebih tinggi, manajer atau pengambil keputusan (Masterson et al., 2000).

Peneliti Colquitt et al. (2001) membagi keadilan organisasional atas tiga konsep yaitu, pertama, keadilan prosedural mempersepsikan bahwa kebijakan dan prosedur diterapkan untuk semua anggota organisasi. Prinsipnya adalah konsistensi, peniadaan bias dan bersifat etis sebagai bentuk integritas (Colquitt et al., 2013; Cui et al., 2018). Kedua, keadilan distributif menjelaskan bahwa hasil didistribusikan secara adil dalam organisasi, misalnya (Colquitt et al., 2013) ekuitas dan kesetaraan. Prinsipnya adalah adanya rasa hormat, dukungan dan keterbukaan. Ketiga, keadilan interaksional berfokus pada sejauh mana seorang karyawan diperlakukan secara adil, hormat dan bermartabat oleh atasan (Colquitt et al., 2013).

Keadilan memainkan peran penting dalam proses perubahan organisasi untuk membangun kemampuan dinamis demi mencapai keunggulan kompetitif yang berkelanjutan (Cui et al., 2018). Penelitian Kwantes dan Bond (2019) menunjukkan bahwa organisasi yang memberlakukan kebijakan yang adil dan transparan serta memutuskan prosedur dan kebijakan organisasi dengan hati-hati dapat mendukung fungsi organisasi yang sehat.

Berbagai penelitian terdahulu telah mengonfirmasi bahwa persepsi keadilan yang diterima oleh individu dari sebuah organisasi berhubungan secara positif dengan kepuasan kerja (Nadiri dan Tanova, 
2010; Al-Zu'bi, 2010; Ouyang et al., 2015; Aksoy dan Yalcinsoy, 2018). Keadilan organisasional juga memengaruhi secara signifikan terbentuknya komitmen karyawan pada organisasi (Crow et al., 2012; Law, 2017; Aksoy dan Yalcinsoy, 2018). Mozhgan et al. (2018) secara khusus mengadakan penelitian terhadap sekelompok perawat rumah sakit di Iran, dan menemukan bahwa keadilan yang dijalankan oleh rumah sakit secara signifikan memengaruhi komitmen perawat pada rumah sakit. Atas dasar berbagai eksplanasi yang dibangun dalam konstruk di atas, maka dapat diajukan hipotesis:

H4a: Keadilan organisasional berpengaruh positif pada kepuasan kerja.

H4b: Keadilan organisasional berpengaruh positif pada komitmen organisasional

\section{Dukungan Atasan}

Dukungan atasan diterima oleh karyawan dari atasan mereka yang berada di tingkat pertama (Yoon dan Lim, 1999). Dukungan tersebut menggambarkan sejauh mana atasan memperhatikan kontribusi karyawan dan kesejahteraan mereka (Powell et al., 2011), termasuk semua hal yang berkaitan dengan pekerjaan dan tingkat interaksi karyawan dengan atasannya (Aksoy et al., 2018).

\section{Peneliti Bhanthumnavin} mengemukakan bahwa dukungan atasan terdiri dari tiga dimensi. Pertama, dukungan informasi berupa penghargaan, hukuman, umpan balik, pengetahuan dan keterampilan.
Kedua, dukungan material terkait bahan, peralatan, waktu, layanan, keuangan dan sumber daya manusia. Ketiga, dukungan emosional yaitu penghargaan, kepedulian, cinta, rasa hormat serta dukungan dalam menghadapi kesulitan, stres dan konflik.

Penelitian terdahulu menemukan bahwa dukungan atasan yang dirasakan oleh karyawan memberikan kepuasan kerja dan selanjutnya memotivasi mereka untuk semakin terlibat dalam organisasi (Aksoy dan Yalcinsoy, 2018). Penelitian Baloyi et al. (2014) menjelaskan bahwa karyawan, terlebih di negara-negara berkembang yang masih memiliki tingkat pendidikan rendah, tidak memahami semua aspek sistem manajemen kinerja yang diterapkan dan dikembangkan oleh organisasi. Atasan langsung memainkan peran penting dalam membantu karyawan untuk memahami dan menginplementasikan isi dan praktek sistem manajemen kinerja sepenuhnya.

Korelasi antara dukungan atasan dan komitmen organisasional juga telah terbukti signifikan (Casper et al., 2011; He at al., 2011; Cakmak, 2012; Li et al., 2018; Aksoy dan Yalcinsoy, 2018). Berbagai hasil penelitian di atas menjelaskan bahwa karyawan yang memperoleh dukungan yang tinggi dari atasan akan merasa puas dengan pekerjaannya. Karyawan yang puas akan lebih berkomitmen pada organisasi dan bekerja lebih efisien sehingga meningkatkan profitabilitas organisasi. Atas dasar penjelasan di atas, maka dapat diajukan hipotesis sebagai berikut: 
H5a: Dukungan atasan berpengaruh positif pada kepuasan kerja.

H5b: Dukungan atasan berpengaruh positif pada komitmen organisasional.

\section{Kerangka Penelitian}

Hubungan antar variabel dalam penelitian ini disajikan dalam gambar 1. Model tersebut menerangkan bahwa OCB dipengaruhi oleh kepuasan kerja dan komitmen organisasional, kepuasan kerja dipengaruhi oleh keadilan organisasional dan dukungan atasan, dan komitmen organisasional dipengaruhi oleh kepuasan kerja, keadilan organisasional dan dukungan atasan.

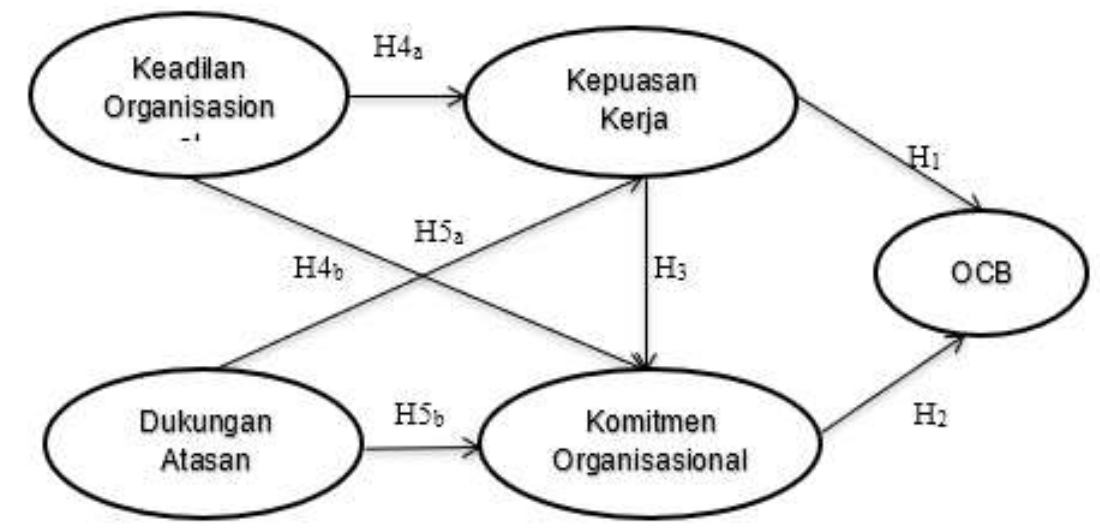

\section{METODE PENELITIAN}

\section{Desain penelitian}

Penelitian ini adalah kuantitatif dengan menggunakan metode survei. Teknik penyampelan menggunakan probability sampling dengan skala Likert 5 poin. Data primer dikumpulkan menggunakan kuesioner. Responden adalah petugas dari
RSJD Surakarta (populasi: 613 orang, sampel: 81 orang) dan RS PKU Muhammadiyah Surakarta (populasi: 897 orang, sampel: 119 orang). Metode analisis data menggunakan Pemodelan Persamaan Struktural (Struktural Equation Modelling SEM). 


\begin{tabular}{|c|c|c|c|c|}
\hline No & Variabel & Definisi & Indikator & Sumber \\
\hline 1 & OCB & $\begin{array}{l}\text { Perilaku sukarela, tidak } \\
\text { termasuk dalam } \\
\text { kebijakan organisasi } \\
\text { dan deskripsi kerja } \\
\text { formal dari anggota } \\
\text { organisasi, tidak secara } \\
\text { langsung diakui dalam } \\
\text { sistim penghargaan } \\
\text { formal namun secara } \\
\text { menyeluruh dapat } \\
\text { meningkatkan fungsi } \\
\text { organisasi secara } \\
\text { efisien dan efektif }\end{array}$ & $\begin{array}{l}\text { Kesukarelaan } \\
\text { membantu rekan kerja. } \\
\text { Tidak mudah } \\
\text { mengeluh. } \\
\text { Menghindari tindakan } \\
\text { yang merugikan di } \\
\text { tempat kerja. } \\
\text { Melampaui persyaratan } \\
\text { minimal. } \\
\text { Sikap responsif dan } \\
\text { keterlibatan konstruktif. }\end{array}$ & 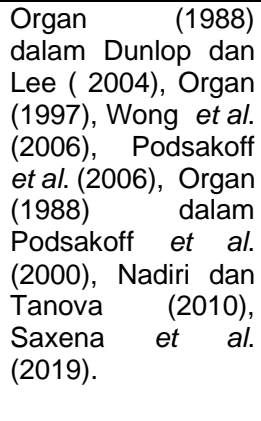 \\
\hline 2 & Kepuasan kerja & $\begin{array}{l}\text { Keadaan emosi positif } \\
\text { karyawan (fisik, mental } \\
\text { dan sosial) yang } \\
\text { memenuhi harapan } \\
\text { mereka berdasarkan } \\
\text { evaluasi atas pekerjaan } \\
\text { dan berguna bagi } \\
\text { kesuksesan, } \\
\text { kebahagiaan dan } \\
\text { produktivitas mereka }\end{array}$ & $\begin{array}{l}\text { Peluang menyalurkan } \\
\text { bakat dan kemampuan } \\
\text { secara optimal } \\
\text { Perlakuan yang baik } \\
\text { dari atasan dan rekan } \\
\text { kerja }\end{array}$ & $\begin{array}{l}\text { Locke (1983) dalam } \\
\text { Mohammad et al. } \\
(2011), \quad \text { Weiss } \\
\text { (2002), Hoş dan } \\
\text { Oksay (2015), } \\
\text { Mohammad et al. } \\
\text { (2011), Saxena et } \\
\text { al. (2019). }\end{array}$ \\
\hline 3 & $\begin{array}{l}\text { Komitmen } \\
\text { organisasional }\end{array}$ & $\begin{array}{l}\text { lkatan psikologis yang } \\
\text { menyatakan komitmen } \\
\text { karyawan untuk tinggal } \\
\text { dalam organisasi serta } \\
\text { mengintegrasikan nilai } \\
\text { dan tujuan organisasi } \\
\text { dengan nilai dan tujuan } \\
\text { karyawan dalam sebuah } \\
\text { interaksi timbal balik }\end{array}$ & $\begin{array}{l}\text { Berkomitmen tetap } \\
\text { bekerja karena rasa } \\
\text { memiliki rumah sakit } \\
\text { Mengalami kerugian } \\
\text { bila meninggalkan } \\
\text { rumah sakit. } \\
\text { Berkomitmen tetap } \\
\text { bekerja karena rumah } \\
\text { sakit telah banyak } \\
\text { berjasa. }\end{array}$ & $\begin{array}{l}\text { Porter et al. (1974), } \\
\text { Meyer dan Allen, } \\
\text { (1991), Meyer dan } \\
\text { Allen (1997) dalam } \\
\text { Aksoy et al. (2018), } \\
\text { Cao et al. (2019), } \\
\text { Wong et al. (2019). }\end{array}$ \\
\hline 4 & $\begin{array}{l}\text { Keadilan } \\
\text { organisasional }\end{array}$ & $\begin{array}{l}\text { Seperangkat aturan dan } \\
\text { norma sosial organisasi } \\
\text { yang dijalankan oleh } \\
\text { pimpinan an atau } \\
\text { pengambil keputusan } \\
\text { dalam organisasi untuk } \\
\text { mendukung fungsi } \\
\text { organisasi yang sehat } \\
\text { melalui r keadilan } \\
\text { prosedural, keadilan } \\
\text { distributif dan keadilan } \\
\text { interaksional }\end{array}$ & $\begin{array}{l}\text { Pemberlakuan sistem, } \\
\text { prosedur dan aturan } \\
\text { secara konsisten } \\
\text { kepada seluruh } \\
\text { karyawan } \\
\text { Imbalan jasa sesuai } \\
\text { tanggungjawab yang } \\
\text { telah dipenuhi } \\
\text { Adanya penghargaan } \\
\text { dan perlakuan yang } \\
\text { baik }\end{array}$ & $\begin{array}{l}\text { Folger dan } \\
\text { Cropanzono } \\
(1998: 110-111) \\
\text { dalam Aksoy et al. } \\
(2018) \text {, Masterson } \\
\text { et al. (2000), } \\
\text { Cohen-Charash } \\
\text { dan Spector (2001), } \\
\text { Colquitt et al. } \\
\text { (2013), Nadiri dan } \\
\text { Tanova (2010). }\end{array}$ \\
\hline 5 & Dukungan atasan & $\begin{array}{lrr}\text { Keadaan } & \text { di } & \text { mana } \\
\text { karyawan mendapatkan } & \text { bantuan dari } & \text { atasan } \\
\text { langsung } & \text { terkait } \\
\text { lakerjaan } & \text { dan } \\
\text { hubungan } & \text { interaksi } \\
\text { yang baik } & \end{array}$ & $\begin{array}{l}\text { Mudah ditemui } \text { ketika } \\
\text { dibutuhkan } \\
\text { Menyediakan sarana } \\
\text { prasarana dan sumber } \\
\text { daya lain yang } \\
\text { dibutuhkan } \\
\text { Bebas untuk berbicara } \\
\text { secara terbuka dan jujur }\end{array}$ & $\begin{array}{l}\text { Yoon dan Lim } \\
\text { (1999), Powell et } \\
\text { al. (2011), Aksoy et } \\
\text { al. (2018), } \\
\text { Bhanthumnavin } \\
\text { (2000), Baloyi et al. } \\
\text { (2014), Guo et al. } \\
\text { (2019). }\end{array}$ \\
\hline
\end{tabular}

\section{Tabel 1. Definisi Operasional Variabel}

\section{Uji Validitas Alat Ukur}

Pengujian validitas dilakukan terhadap 30 responden dari RS PKU Muhammadiyah Surakarta. Metode menggunakan analisis model pengukuran eksogen dan endogen. Teknik analisis data menggunakan analisis SEM dengan aplikasi AMOS versi 16. 
Pengukuran Model Eksogen

Model pengukuran eksogen ditunjukkan dalam gambar 2 berikut.

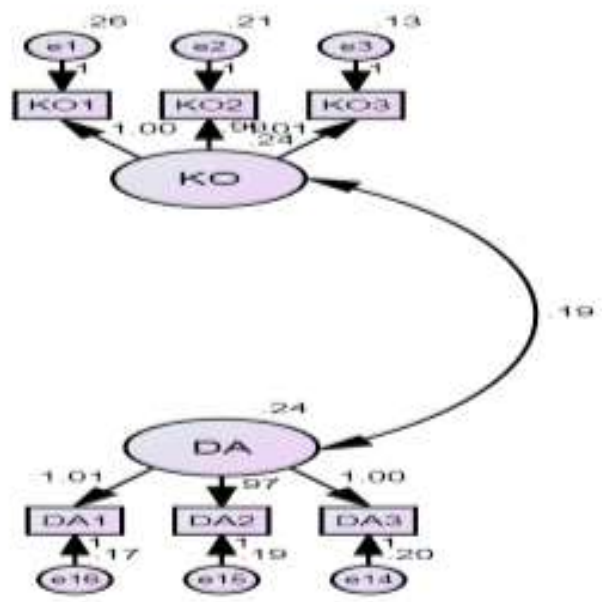

Gambar 2. Model Pengukuran Eksogen

Dari gambar 2 diperoleh hasil uji Goodness dengan data. Hasil pengujian ditampilkan of Fit untuk menguji kesesuaian model dalam Tabel 2.

\begin{tabular}{lccl}
\hline \multicolumn{1}{c}{ Fit Index } & Nilai Kriteria & Output Nilai & \multicolumn{1}{c}{ Keterangan } \\
\hline GFI & $\geq 0,90$ & 0,929 & Baik \\
RMSEA & $\leq 0,08$ & 0,142 & Buruk \\
AGFI & $\geq 0,90$ & 0,812 & Marginal \\
TLI & $\geq 0,90$ & 0,875 & Marginal \\
NFI & $\geq 0,90$ & 0,919 & Baik \\
CFI & $\geq 0,90$ & 0,933 & Baik \\
CMIN/DF & $\leq 2,00$ & 1,985 & Baik \\
RMR & $\leq 0,03$ & 0,026 & Baik \\
\hline
\end{tabular}

Sumber: Nilai kriteria menurut Hair et al. (2010) dan output nilai menurut data primer yang diolah, 2020

Tabel 2 Hasil Goodness of Fit Model Pengukuran Eksogen

Tabel 2 menunjukkan bahwa tujuh nilai indeks dalam Goodness of Fit dinyatakan baik. Hasil tersebut telah memenuhi hampir semua nilai standar Goodness of Fit, sehingga dapat disimpulkan bahwa model yang digunakan sudah sesuai dengan data
Hasil uji validitas kuesioner ditunjukkan dalam kolom estimates dengan melihat regression weight dari masing-masing item variabel tersebut. Hasil uji validitas kuesioner Model Eksogen ditunjukkan dalam Tabel 3. 


\begin{tabular}{ccc}
\hline Indikator & Regression Weight & Keterangan \\
\hline $\mathrm{KO}_{1}$ & 1,000 & Valid \\
$\mathrm{KO}_{2}$ & 0,928 & Valid \\
$\mathrm{KO}_{3}$ & 1,015 & Valid \\
& & \\
$\mathrm{DA}_{1}$ & 1,000 & Valid \\
$\mathrm{DA}_{2}$ & 0,778 & Valid \\
$\mathrm{DA}_{3}$ & 1,091 & Valid \\
\hline
\end{tabular}

Sumber : Hasil uji validitas kuesioner Model Eksogen, 2020.

Tabel 3 Hasil Uji Validitas Kuesioner Model Eksogen

Berdasarkan Tabel 3, dijelaskan bahwa berkorelasi erat satu sama lain, enam item kuesioner untuk variabel eksogen menggambarkan variabel yang diwakilinya. adalah valid. Uji tersebut dikatakan valid Pengukuran Model Endogen

karena seluruh item memiliki regression Model pengukuran endogen ditunjukkan weight lebih besar dari 0,40. Hal ini dalam gambar 3 berikut. mengindikasikan bahwa indikator variabel

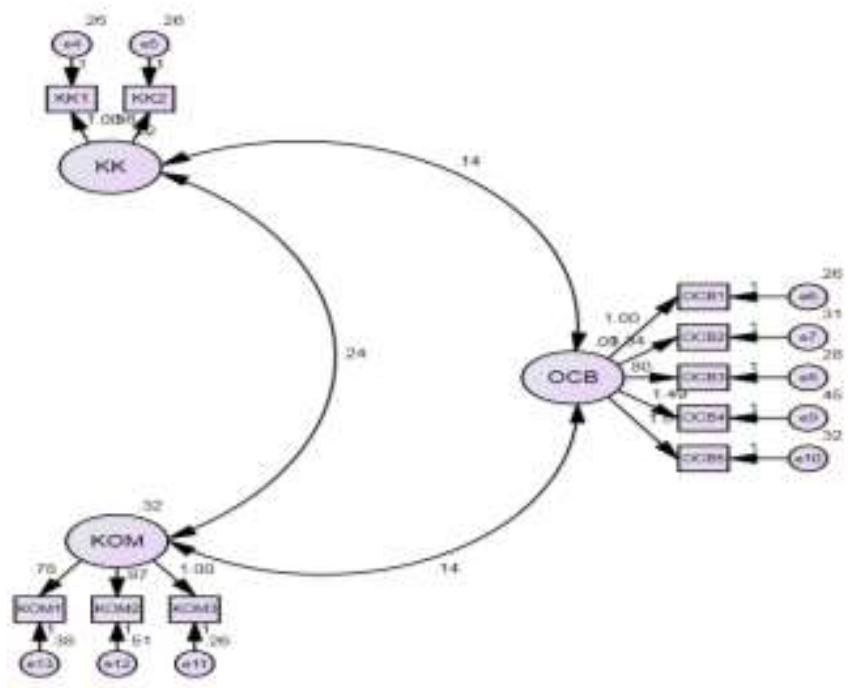

Gambar 3 Model Pengukuran Endogen

Dari gambar 3 dilakukan uji Goodness of Fit untuk menguji kesesuaian model dengan data. Hasil pengujian ditampilkan dalam Tabel 4. 


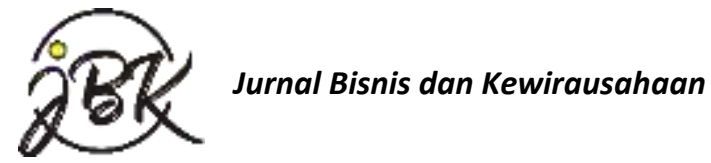

Vol-13/No-1/April/2020

\begin{tabular}{lccl}
\hline \multicolumn{1}{c}{ Fit Index } & Nilai Kriteria & Output Nilai & \multicolumn{1}{c}{ Keterangan } \\
\hline GFI & $\geq 0,90$ & 0,930 & Baik \\
RMSEA & $\leq 0,08$ & 0,079 & Baik \\
AGFI & $\geq 0,90$ & 0,880 & Marginal \\
TLI & $\geq 0,90$ & 0,890 & Marginal \\
NFI & $\geq 0,90$ & 0,870 & Marginal \\
CFI & $\geq 0,90$ & 0,922 & Baik \\
CMIN/DF & $\leq 2,00$ & 2,227 & Buruk \\
RMR & $\leq 0,03$ & 0,030 & Baik \\
\hline
\end{tabular}

Sumber: Nilai kriteria menurut Hair et al. (2010) dan output nilai menurut data primer yang diolah, 2020

Tabel 4 Hasil Goodness of Fit Model Pengukuran Endogen

Tabel 4 menunjukkan bahwa tujuh nilai indeks dalam Goodness of Fit dinyatakan baik. Hasil tersebut telah memenuhi hampir semua nilai standar Goodness of Fit, sehingga dapat disimpulkan bahwa model yang digunakan sudah sesuai dengan data.
Hasil uji validitas ditunjukkan dalam kolom estimates dengan melihat regression weight dari masing-masing item variabel tersebut. Hasil uji validitas kuesioner Model Endogen ditunjukkan dalam Tabel 5.

\begin{tabular}{ccc}
\hline Indikator & Regression Weight & Keterangan \\
\hline $\mathrm{OCB}_{1}$ & 1,000 & Valid \\
$\mathrm{OCB}_{2}$ & 0,890 & Valid \\
$\mathrm{OCB}_{3}$ & 1,000 & Valid \\
$\mathrm{OCB}_{4}$ & 0,881 & Valid \\
$\mathrm{OCB}_{5}$ & 0,554 & Valid \\
& & \\
$\mathrm{KK}_{1}$ & 0,840 & Valid \\
$\mathrm{KK}_{2}$ & 0,882 & Valid \\
& & \\
$\mathrm{KOM}_{1}$ & 1,000 & Valid \\
$\mathrm{KOM}$ & 1,192 & Valid \\
KOM & 1,336 & Valid \\
\hline Sumber : Hasil uji validitas kuesioner Model Endogen, 2020. \\
Tabe 5 Hasil Uji Validitas Kuesioner Model Endogen
\end{tabular}

Berdasarkan Tabel 5 di atas, dapat dijelaskan bahwa 10 item kuesioner adalah valid. Uji tersebut dinyatakan valid karena memiliki regression weight lebih besar dari 0,40 . Hal ini mengindikasikan bahwa indikator variabel berkorelasi erat satu sama lain, menggambarkan variabel yang diwakilinya.

\section{Uji Reliabilitas Alat Ukur}

Pengujian reliabilitas dilakukan terhadap 30 sampel responden dari RS.PKU Muhammadiyah Surakarta. Teknik pengujian menggunakan SPSS. Hasil uji reliabilitas kuesioner ditunjukkan dalam Tabel 6. 


\begin{tabular}{lcl}
\hline \multicolumn{1}{c}{ Indikator } & Koefisien Alpha & Keterangan \\
\hline OCB & 0,831 & Reliabel \\
Kepuasan Kerja (KK) & 0,638 & Reliabel \\
Komitmen Organisasional (KOM) & 0,842 & Reliabel \\
Keadilan Organisasional (KO) & 0,909 & Reliabel \\
Dukungan Atasan (DA) & 0,811 & Reliabel \\
\hline
\end{tabular}

Sumber : Hasil uji reliabilitas kuesioner, 2020.

Tabel 6 Hasil Uji Reliabilitas Kuesioner

Tabel 6 menunjukkan bahwa semua butir

D. Hasil Penelitian

kuesioner mempunyai nilai reliabilitas lebih

Hasil pengujian Goodness of Fit dan besar dari 0,6 sehingga reliabel digunakan Signifikansi Hubungan Antar Variabel untuk mengambil data.

ditampilkan dalam Tabel 7 dan Tabel 8

\begin{tabular}{lccl}
\hline \multicolumn{1}{c}{ Fit Index } & Nilai Kriteria & Output Nilai & \multicolumn{1}{c}{ Keterangan } \\
\hline GFI & $\geq 0,90$ & 0,917 & Baik \\
RMSEA & $\leq 0,08$ & 0,060 & Baik sekali \\
AGFI & $\geq 0,90$ & 0,871 & Marginal \\
TLI & $\geq 0,90$ & 0,931 & Baik \\
NFI & $\geq 0,90$ & 0,888 & Marginal \\
CFI & $\geq 0,90$ & 0,949 & Baik sekali \\
CMIN/DF & $\leq 2,00$ & 1,706 & Baik sekali \\
RMR & $\leq 0,03$ & 0,023 & Baik \\
\hline
\end{tabular}

Sumber: Nilai kriteria menurut Hair et al. (2010) dan output nilai menurut data primer yang diolah, 2020

Tabel 7 Hasil Goodness of Fit Model

Tabel 7 menunjukkan bahwa semua nilai standar Goodness of Fit, sehingga dapat indeks dalam Goodness of Fit dinyatakan fit. disimpulkan bahwa model yang digunakan Hasil tersebut telah memenuhi semua nilai sudah sesuai dengan data.

\begin{tabular}{lcc}
\hline Hubungan Antar Variabel & Nilai Probabilitas \\
\hline $\mathrm{KK} \rightarrow \mathrm{OCB}$ & 0,006 \\
$\mathrm{KOM} \rightarrow \mathrm{OCB}$ & 0,861 \\
$\mathrm{KK} \rightarrow \mathrm{KOM}$ & 0,156 \\
$\mathrm{KO} \rightarrow \mathrm{KK}$ & 0,783 \\
$\mathrm{KO} \rightarrow \mathrm{KOM}$ & 0,511 \\
$\mathrm{DA} \rightarrow \mathrm{KK}$ & 0,928 \\
$\mathrm{DA}$ & $\rightarrow \mathrm{KOM}$ & $\rightarrow$
\end{tabular}

Sumber: Data primer yang diolah, 2020

Tabel 8 Hasil Analisis Uji Signifikansi Hubungan Antar Variabel 
Model penelitian ditunjukkan dalam gambar 4 berikut.

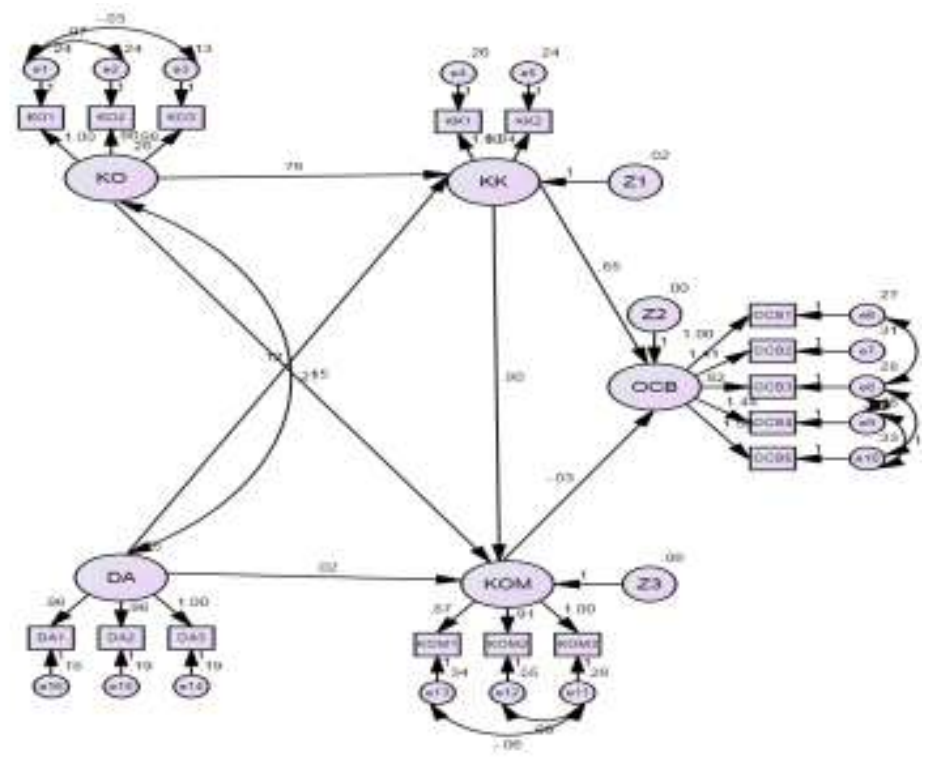

Gambar 4 Hasil Model Hubungan Antar Variabel

\section{Analisis Data}

Hasil uji signifikansi pengaruh kepuasan kerja terhadap OCB memiliki nilai probabilitas sebesar 0,006. Hal ini dapat disimpulkan bahwa kepuasan kerja berpengaruh positif pada OCB ( $p=0,006 ; p<0,05)$. Maka hipotesis 1 terdukung oleh datanya. Hasil uji signifikansi pengaruh komitmen organisasional terhadap OCB memiliki nilai probabilitas sebesar 0,861 . Hal ini dapat disimpulkan bahwa komitmen organisasional tidak berpengaruh pada OCB $(p=0,861 ; p>$ $0,05)$. Maka hipotesis 2 tidak terdukung oleh datanya.

Hasil uji signifikansi pengaruh kepuasan kerja terhadap komitmen organisasional memiliki nilai probabilitas sebesar 0,156. Hal ini dapat disimpulkan bahwa kepuasan kerja tidak berpengaruh pada komitmen organisasional ( $p=0,156 ; p>0,05)$. Maka hipotesis 3 tidak terdukung oleh datanya. Hasil uji signifikansi pengaruh keadilan organisasional terhadap kepuasan kerja memiliki nilai probabilitas dengan simbol ***. Hal ini dapat disimpulkan bahwa keadilan organisasional berpengaruh positif secara signifikan terhadap kepuasan kerja $\left(p={ }^{* *} ; p\right.$ $<0,05)$. Maka hipotesis 4a terdukung oleh datanya. Hasil uji signifikansi pengaruh keadilan organisasional terhadap komitmen organisasional memiliki nilai probabilitas sebesar 0,783. Hal ini dapat disimpulkan bahwa keadilan organisasional tidak berpengaruh pada komitmen organisasional ( $p=0,783 ; p>0,05)$. Maka hipotesis $4 b$ tidak terdukung oleh datanya. 
Hasil uji signifikansi pengaruh dukungan atasan terhadap kepuasan kerja memiliki nilai probabilitas sebesar 0,511. Hal ini dapat disimpulkan bahwa dukungan atasan tidak berpengaruh terhadap kepuasan kerja ( $\mathrm{p}=$ 0,511; $\mathrm{p}>0,05)$. Maka hipotesis $5 \mathrm{a}$ terdukung oleh datanya. Hasil uji signifikansi pengaruh dukungan atasan terhadap komitmen organisasional memiliki nilai probabilitas sebesar 0,928. Hal ini dapat disimpulkan bahwa dukungan atasan tidak berpengaruh pada komitmen organisasional $(p=0,928 ; p>0,05)$. Maka hipotesis 5b tidak terdukung oleh datanya.

\section{Pembahasan}

Kepuasan kerja berpengaruh positif terhadap terbentuknya OCB. Hal tersebut sejalan dengan hasil studi terdahulu yang menyatakan bahwa seorang karyawan yang merasa puas dengan pekerjaannya akan berkomitmen dan semakin terlibat untuk melakukan OCB (Swaminathan et al., 2013). Komitmen organisasional tidak berpengaruh pada OCB. Hasil ini bertentangan dengan penelitian Zayas-Ortiz et al. (2015) yang menyatakan adanya pengaruh komitmen organisasional yang kuat terhadap pembentukan OCB. Penyebab tidak adanya signifikansi ini dapat dipahami mengingat tingkat persentase komitmen berkelanjutan cukup tinggi. Artinya, cukup banyak pegawai yang memutuskan tetap bekerja di rumah sakit tanpa memberikan kontribusi lebih bagi efisiensi dan efektivitas organisasi melalui OCB. Pegawai memilih tetap bekerja di rumah sakit karena pertimbangan manfaat yang diperoleh lebih besar dibandingkan kerugian (Meyer dan Allen, 1991).

Kepuasan kerja tidak berpengaruh pada komitmen organisasional. Hasil penelitian ini berbeda dengan berbagai hasil penelitian terdahulu. Hal ini dapat dimaknai bahwa perbedaan karakteristik obyek dan tempat penelitian dapat menyebabkan pegawai tidak berkomitmen pada organisasi. Keadilan organisasional berpengaruh positif secara signifikan pada kepuasan kerja. Hasil ini mengonfirmasi berbagai penelitian terdahulu bahwa terdapat korelasi positif yang signifikan antara keadilan organisasional dan kepuasan kerja (Nadiri dan Tanova, 2010; AlZu'bi, 2010; Ouyang et al., 2015; Aksoy dan Yalcinsoy, 2018).

Keadilan organisasional tidak berpengaruh terhadap komitmen organisasional. Hasil ini berbeda dengan berbagai penelitian terdahulu. Hal ini dapat dimungkinkan bahwa komitmen pada organisasi tidak hanya ditentukan oleh tiga faktor keadilan organisasional yang terdiri dari konsistensi, finansial dan relasi sosial yang baik. Menurut Masterson et al. (2000), faktor-faktor lain seperti promosi jenjang karir, pelibatan karyawan dalam pengambilan keputusan untuk membuat inovasi/perubahan dapat lebih memotivasi pegawai untuk berkomitmen pada organisasi.

Dukungan atasan tidak berpengaruh pada kepuasan kerja. Tidak adanya signifikansi dapat dimungkinkan karena kurang adanya dukungan atasan langsung terkait 
ketersediaan sarana dan prasarana yang dibutuhkan oleh karyawan untuk bekerja dan kurang adanya kebebasan bagi karyawan untuk berbicara secara terbuka dan jujur kepada atasan langsung. Dukungan atasan tidak berpengaruh terhadap terbentuknya komitmen kayawan pada organisasi.. Penyebab tidak adanya signifikansi antara kedua konstruk tersebut mungkin disebabkan karena adanya perbedaan obyek penelitian. Perbedaan tempat penelitian maupun latar belakang budaya yang menyebabkan perbedaan perilaku individu dapat memberikan hasil penelitian yang berbeda.

\section{E. Kesimpulan}

Kesimpulan yang bisa diambil dari penelitian ini adalah untuk membentuk OCB, faktor yang harus dibangun adalah kepuasan kerja. Terbentuknya kepuasan kerja disebabkan karena adanya faktor keadilan organisasional yang diterima oleh karyawan dari rumah sakit.

\section{Keterbatasan Penelitian}

Keterbatasan dari penelitian ini adalah terkait ruang lingkup penelitian. Berdasarkan hasil penentuan populasi dengan menggunakan probability cluster sampling, populasi penelitian ini hanya terbatas di Kecamatan Jebres (RSJD Surakarta) dan Kecamatan Banjarsari (RS.PKU Muhammmadiyah Surakarta). Keterwakilan populasi penelitian yang terbatas tersebut dapat mengurangi tingkat generalisasi penelitian. Oleh karena itu, penelitian di masa yang akan datang perlu mengakomodasi wilayah populasi yang lebih luas agar hasil penelitian mempunyai generalisasi yang baik.

\section{Impilkasi Manajerial}

Manajemen RSJD Surakarta dan RS.PKU.Muhammadiyah Surakarta perlu meningkatkan kesetiaan karyawan melalui OCB. Hal yang dapat dilakukan antara lain dengan memperbanyak sistem kerja kolektif untuk mengurangi beban kerja, jadual dan beban kerja yang fleksibel sehingga memungkinkan karyawan terlibat dalam kegiatan di luar tugas pokok, penghargaan khusus kepada karyawan yang telah menunjukkan OCB, pelibatan karyawan dalam pengambilan keputusan serta pendelegasian tugas dari atasan kepada anggota.

\section{Implikasi untuk Peneliti Masa Depan}

Penelitian serupa perlu diterapkan pada seluruh rumah sakit di wilayah Kota Surakarta, sehingga hasil temuan selanjutnya dapat digeneralisasikan secara lebih baik dalam konteks wilayah tersebut. Masih sedikit jurnal atau penelitian yang membahas OCB dengan menggunakan obyek seluruh petugas rumah sakit. Hasil penelitian yang akan datang diperlukan untuk mengkonfirmasi hasil penelitian ini.

\section{REFERENSI}

Aksoy, Cenk \& Ayhan Yalcinsoy. (2018). Investigation on the relationship between job satisfication, organizational 
commitment, organizational justice and supervisor support: an applicatichinyereon in the health sector. Journal of Management Research, Vol. 10, No. 1.

Al-Zu'bi, H. A. (2010). A study of relationship between organizational justice and job satisfaction. International Journal of Business and Management, Vol. 5, No. 12, pp.102.

Anonim. 2019. "Undang-undang RI No.44 Tahun 2009 Tentang Rumah Sakit", (online),http://hukor.kemkes.go.id/upload s/produk hukum/PMK/No 4 Th 2019 t tg Standar Teknis Pelayanan Dasar P ada Standar Pelayanan Minimal Bidan g Kesehatan1.pdf, diakses 22 Nopember 2019.

Baloyi, S., Van Waveren, C.C., Chan, K.Y. (2014). The role of supervisor support in predicting employee job satisfaction from their perception of the performance management system: a test of competing models in engineering environments. South African Journal of Industrial Engineering, Vol.25, No.1, 85-95.

Bhanthumnavin, D. (2000). Importance of supervisory social support and its implications for HRD in Thailand. Psychology and Developing Societies, Vol. 12, 155-166.

Çakmak-Otluoğlu, K. Övgü. (2012). Protean and boundaryless career attitudes and organizational commitment: the effects of perceived support. Journal of Vocational Behavior, Vol.80, 638-646.
Cao, Yudi, Jingying Liu, Kejia Liu, Mengyu Yang, Yanhui Liu. (2019). The mediating role of organizational commitment between calling and work engagement of nurses: a cross sectional study. International Journal of Nursing Sciences, Vol.6, 309-314.

Casper, Wendy Jean, Christopher Harris, Amy Taylor-Bianco, Julie Holliday Wayne. 2011. Work family conflict, perceived supervisor support and organizational commitment among Brazilian professionals. Journal of Vocational Behavior, Vol. 79, 640-652.

Chun, J. S., Shin, Y., Choi, J. N., Kim, M. S. (2013). How does corporate ethics contribute to firm financial performance? The mediating role of collective organizational commitment and organizational citizenship behavior. Journal of Management, Vol.39, 853-877. Cohen-Charash, Yochi \& Paul E. Spector. (2001). The role of justice in organizations: A meta analysis. Organizational Behavior and Human Decision Processes, Vol. 86, No. 2, pp. 278-321.

Colquitt, J. A., Conlon, D. E., Wesson, M. J., Porter, C. O. L. H., Ng, K. Y. (2001). Justice at the millennium: a meta analytic review of 25 years of organizational justice research. Journal of Applied Psychology, Vol.86, No.3, 425-445.

Colquitt, J. A., Scott, B. A., Rodell, J. B., Long, D. M., Zapata, C. P., Conlon, D. E., Wesson, M. J. (2013). Justice at the 
millennium, a decade later: a meta analytic test of social exchange and affect based perspectives. Journal of Applied Psychology, Vol.98, No.2, 199-236.

Crow M, Lee C-B \& Joo J-J. (2012). Organizational justice and organizational commitment among South Korean police officers: an investigation of job satisfaction as a mediator. Policing: An International Journal of Police Strategies and Management. Vol.35, 402-423.

Cui,Yu, Hao Jiao, Guiqin Wang, Guozhen Zhao. (2018). Organizational justice and management trustworthiness during organizational change: interactions of benevolence, integrity, and managerial approaches. Information Processing and Management.

Dunlop, Patrick D., Kibeom Lee. (2004). Workplace deviance, organizational citizenship behavior, and business unit performance: the bad apples do spoil the whole barrel. Journal of Organizational Behavior, No.25, 67-80.

Guo, Ming, Shuzhen Liu, Fulei Chu, Long Ye, Qichao Zhang. (2019). Supervisory and coworker support for safety: buffers between job insecurity and safety performance of high speed railway drivers in China. Safety Science, Vol.117, 290298.

Hoş, C. \& Oksay, A. (2015). Hemşirelerde örgütsel bağlıık ile iş tatmini ilişkisi, süleyman demirel üniversitesi iktisadi ve idari bilimler fakültesi dergisi, Vol.20, No.4, 1-24.
Kirkman, B.L. \& Shapiro, D.L. (2001). The impact of cultural values on job satisfaction and organizational commitment in self-managing work teams: the mediating role of employee resistance. Academy of Management Journal, Vol.44, No.3, 557-569..

Kwantes, Catherine T. \& Michael H. Bond. (2019). Organizational justice and autonomy as moderators of the relationship between social and organizational cynicism. Personality and Individual Differences.

Law, Z. L. E. M. Rob. (2017). Linking leadership and justice to organizational commitment - the mediating role of collective identity in the hotel industry. International Journal of Contemporary Hospitality Management, Vol. 29, Iss 4 pp.

Li, Yongzhan, Gloria Castaño, Yongxin Li. (2018). Perceived supervisor support as a mediator between Chinese university teachers' organizational justice and affective commitment. Social Behavior and Personality, Vol.46, No.8, 13851396.

Masterson, Suzanne S., Kyle Lewis, Barry M. Goldman, M. Susan Taylor. (2000). Integrating justice and social exchange: The differing effects of fair procedures and treatment on work relationships. Academy of Management Journal, Vol.43, No.4, pp. 738-748.

Meyer, J.P. \& Allen, N.J. (1991). A three component conceptualization of 
organizational commitment. Human Resource Management Review, Vol.78, No.1, 61-89.

Mohammad, Jehad, Farzana Quoquab Habib, Mohmad Adnan Alias. (2011). Job satisfaction and organisational citizenship behaviour: an empirical study at higher learning institutions. Asian Academy of Management Journal, Vol. 16, No. 2, 149165.

Mozhgan Fardid, Nahid Hatam, Zahra Kavosi. (2018). A path analysis of the effects of nurses' perceived organizational justice, organizational commitment, and job satisfaction on their turnover intention. Nursing Midwifery Studies 7:157-62.

Nadiri, H. \& Cem Tanova. (2010). An investigation of the role of justice in turnover intentions, job satisfaction, and organizational citizenship behavior in hospitality industry. International Journal of Hospitality Management, Vol.29, No.1, 33-41.

Ocampo, Lanndon, Venus Acedillo, Alin Mae Bacunador, Charity Christine Balo, Yvonne Joreen Lagdameo, Nickha Shanen Tupa. (2018). A historical review of the development of organizational citizenship behavior (OCB) and its implications for the twenty first century. Personnel Review, Vol. 47, Issue: 4, pp.821-862.

Organ, D.W. (1997). Organizational citizenship behavior: it's construct clean up time. Human Performance, Vol.10, 8597.
Ouyang, Zhongming, Jinyan Sang, Ping Li, Jiaxi Peng. (2015). Organizational justice and job insecurity as mediators of the effect of emotional intelligence on job satisfaction: a study from China. Personality and Individual Differences, Vol.76, 147-152.

Podsakoff, P.M., MacKenzie, S.B., Paine, J.B., Bachrach, D.G. (2000). Organizational citizenship behaviors: a critical review of the theoretical and empirical literature and suggestions for future research. Journal of Management, Vol. 26, No. 3, pp. 513-563.

PodsakoV, Philip M., William H. Bommer, Nathan P. PodsakoV, Scott B. MacKenzie. 2006. Relationships between leader reward and punishment behavior and subordinate attitudes, perceptions, and behaviors : a meta-analytic review of existing and new research. Organizational Behavior and Human Decision Processes, Vol.99, 113-142.

Porter, L.W. Steers, R.M. Mowday, R.T., Boulian, P.V. (1974). Organizational commitment, job satisfaction, and turnover among psychiatric technicians. Journal of Applied Psychology, Vol. 59. No. 5, pp. 603-609.

Powell, Thomas C., Dan Lovallo, Craig R. Fox. (2011). Behavioral strategy. Strategic Management Journal, Vol.32, 1369-1386.

Salanova M., Lorente L., Chambel M.J., Mart_ınez I.M. (2011). Linking transformational leadership to nurses' 
extra-role performance: the mediating role of self efficacy and work engagement. Journal of Advanced Nursing, Vol. 67, 2256-2266.

Saxena, Sonal, Kalpana Tomarb, Shivangi Tomar. (2019). Impact of job satisfaction on organizational citizenship behavior. SSRN Electronic Journal Volume Issue.

Swaminathan, S. \& Jawahar, P. D. (2013). Job satisfaction as a predictor of organizational citizenship behavior: an empirical study. Global Journal of Business Research, Vol.7, No.1, pp. 7180.

Weiss, H.M. (2002). Deconstructing job satisfaction separating evaluations, beliefs and affective experiences. Human Resources Management Review, Vol.12, No.2, 173-194.

Wong, IpKin Anthony, Erdan Ma, Suk Ha Grace Chan, GuoQiong Ivanka Huang, Tong Zhao. (2019). When do satisfied employees become more committed? A multilevel investigation of the role of internal service climate. International Journal of Hospitality Management, Vol.82, 125-135.

Wong, Y. T., Ngo, H. Y., Wong, C. S. (2006). Perceived organizational justice, trust, and OCB: a study of Chinese workers in joint ventures and state owned enterprises. Journal of World Business, Vol.41, No.4, 344-355.

Yao, Tang, Qi Qiu, Yigang Wei. 2019. Retaining hotel employees as internal customers : effect of organizational commitment on attitudinal and behavioral loyalty of employees. International Journal of Hospitality Management Vol.76, 1-8.

Yoon, Jeongkoo \& Jun-Cheol Lim. (1999). Organizational support in the workplace : the case of Korean hospital employees. Human Relations, Vol.52, No.7, 923-945.

Yucel, Ilhami \& Cetin Bektas. (2012). Job satisfaction, organizational commitment and demographic characteristics among teachers in Turkey: younger is better? Procedia - Social and Behavioral Sciences, Vol.46, 1598 - 1608.

Zayas-Ortiz, Maria, Rosario Ernesto, Marquez Eulalia, Colón Gruñeiro Pablo. (2015). Relationship between organizational commitments and organizational citizenship behaviour in a sample of private banking employees. International Journal of Sociology and Social Policy, Vol. 35, Iss 1/2 pp. - 